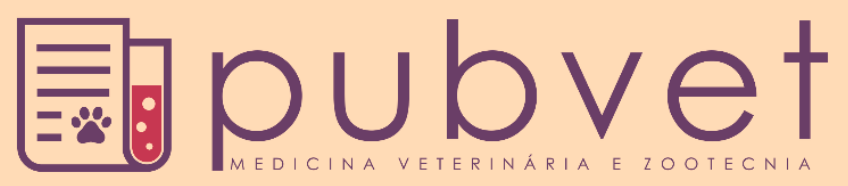

https://doi.org/10.31533/pubvet.v15n12a1000.1-10

\title{
Efeito do cultivar e do grau de maturidade dos grãos sobre os espectros NIR de silagens de sorgo
}

\author{
Valcicleide Oliveira dos Santos ${ }^{1 *}$ (D) Marco Aurélio Delmondes Bomfim ${ }^{2} \mathbb{D}$, Sueli Freitas dos \\ Santos $^{3(\mathbb{D})}$, Rafael Gonçalves Tonucci ${ }^{2}{ }^{(\mathbb{D}}$, Ana Clara Rodrigues Cavalcante ${ }^{2}{ }^{(\mathbb{D}}$, Ana Karina de \\ Lima Chaves ${ }^{1}$ (D), Patrício Leandro Pereira ${ }^{1}$ (i)
}

${ }^{1}$ Mestranda em Zootecnia, Universidade Estadual Vale do Acaraú. Sobral-CE, Brasil.
${ }^{2}$ Pesquisador(a) na Empresa Brasileira de Pesquisa Agropecuária Caprinos e Ovinos. Sobral - CE, Brasil.
${ }^{3}$ Pós doutorado na Empresa Brasileira de Pesquisa Agropecuária Caprinos e Ovinos. Sobral - CE, Brasil.
${ }^{*}$ Autor para correspondência E-mail: valcicleideoliveira@hotmail.com

Resumo. Objetivou-se, avaliar a similaridade espectral entre cultivares de sorgo em diferentes estádios de maturação dos grãos, visando o desenvolvimento de modelos utilizando espectroscopia de refletância no infravermelho próximo (NIRS). Para a ensilagem utilizou-se os sorgos BRS 658 e BRS Ponta Negra, em mini silos de PVC, nos estádios de maturação dos grãos leitoso, pastoso, farináceo e duro. As variáveis foram estudadas pela técnica de Análise de Componentes Principais (PCA), e classificação usando a Modelagem Independente por Analogia de Classe (SIMCA) utilizando o software Unscrambler. A similaridade de amostras da silagem do BRS 658 com o banco de dados do BRS Ponta negra foi de 5\% e do BRS Ponta Negra em relação as do BRS 658 a similaridade foi de $65 \%$. Os dados demonstram grande similaridade do BRS Ponta Negra entre os estádios dos grãos leitoso e pastoso. A análise da PCA, demonstrou uma semelhança entre as amostras no estádio leitoso das duas cultivares, no estádio leitoso com pastoso, farináceo e duro. A análise exploratória indica que é importante considerar a cultivar e os estádios de maturidade dos grãos para o desenvolvimento de modelos NIR de silagem de sorgo. A análise dos espectros NIR das cultivares BRS 658 e BRS Ponta Negra, bem como dos estádios de maturidade no momento da ensilagem indicam que as dissimilaridades observadas agregam variabilidade ao modelo, mas que, ao mesmo tempo, não são tão significativas a ponto de sugerirem desenvolvimento de modelos separados, permitindo a fusão dos dados para desenvolvimento de um único modelo NIR.

Palavras chave: Análise multivariada, espectroscopia, gramíneas, SIMCA

\section{Effect of cultivar and grain maturity on NIR spectra of sorghum silages}

Abstract. The objective of this study was to evaluate the spectral similarity between sorghum cultivars at different stages of grain maturation, aiming at the development of models using near infrared reflectance spectroscopy (NIRS). For ensiling, sorghums BRS 658 and BRS Ponta Negra were used in PVC mini silos, in the stages of maturation of milky, pasty, farinaceous and hard grains. The variables were studied using the Principal Component Analysis (PCA) technique, and classification using Independent Class Analogy Modeling (SIMCA) using the Unscrambler software. The similarity of silage samples from BRS 658 with the BRS Ponta Negra database was 5\% and from BRS Ponta Negra to BRS 658 the similarity was $65 \%$. The data show great similarity of BRS Ponta Negra between the milky and pasty grain stages. The PCA analysis showed a similarity between the samples in the milky stages of the two cultivars, in the milky stage with pasty, farinaceous and hard. The exploratory analysis indicates that it is important to consider the cultivar and 
the grain maturity stages for the development of NIR sorghum silage models. The analysis of the NIR spectra of the cultivars BRS 658 and BRS Ponta Negra, as well as the stages of maturity at the time of ensiling indicate that the dissimilarities observed add variability to the model, but that, at the same time, they are not so significant as to suggest development of separate models, allowing the merging of data to develop a single NIR model.

Keywords: Multivariate analysis, spectroscopy, grasses, SIMCA

\section{Introdução}

A exploração da pecuária brasileira tem como base o uso de pastagens, que é a forma mais barata de alimentar os ruminantes. Entretanto, essas sofrem variações quantitativas e qualitativas de acordo com as estações do ano, sendo fatores limitantes para a adequada alimentação de pequenos ruminantes no semiárido nordestino (Ribeiro et al., 2009) e para superar essa limitação, têm se utilizado a técnica de ensilagem (Avelino et al., 2011; Neumann et al., 2007; Restle et al., 2006).

O sorgo é uma importante cultura forrageira devido ao seu potencial de produção de forragem, aliado ao alto valor nutritivo de suas silagens (Faustino et al., 2018; Ribeiro et al., 2007). Atualmente vários híbridos e variedades estão disponíveis, com grandes variações quanto à produção e concentração de nutrientes, tornando importante estudos comparativos que combinem características agronômicas e nutricionais (Penna et al., 2011; Silva et al., 2013).

O uso da espectroscopia da reflectância no infravermelho próximo (NIRS), vem se mostrando como uma ferramenta que possibilita a realização de análises químicas com precisão, rapidez e baixo custo (Prieto et al., 2006). No entanto, diferenças físico-químicas entre cultivares, como as relativas ao estádio de maturação das plantas, podem afetar sua composição e o desenvolvimento de modelos mais robustos. Assim, para a construção de modelos NIR é fundamental estudos exploratórios levando em conta o efeito dessas características no material de estudo, para orientar se as cultivares podem ser incluídas em um único modelo, ou se há necessidade de individualizar a modelagem.

A análise de componentes principais (PCA) e a classificações usando Modelagem Independente por Analogia de Classe (SIMCA) são ferramentas para o estudo do conjunto de dados espectrais, explorando a presença ou ausência de agrupamentos naturais e a existência de similaridades entre as amostras ( $\underline{\mathrm{Fu}}$ \& Ying, 2016).

Objetivou-se, avaliar a similaridade espectral entre cultivares de sorgo em diferentes estádios de maturação dos grãos, visando o desenvolvimento de modelos utilizando espectroscopia de refletância no infravermelho próximo.

\section{Material e métodos}

\section{Cultivares e área experimental}

Foram avaliadas duas cultivares comerciais de sorgo - variedade BRS Ponta Negra e o híbrido BRS 658, amplamente utilizadas no nordeste brasileiro. O BRS Ponta Negra possui como característica agronômica porte alto, resistência ao acamamento, tolerância a seca, panícula semiaberta e presença de tanino. Possui ciclo fenológico médio de 85 a 95 dias para atingir ponto de ensilagem. O sorgo BRS 658 é adaptado para produção de forragem, apresentando porte alto, ciclo de 100 dias, possui colmo secos com excelente padrão fermentativo, resistência ao acamamento o que confere altas produtividades de massa.

O experimento foi conduzido na Fazenda Três Lagoas, pertencente à Embrapa Caprinos e Ovinos,

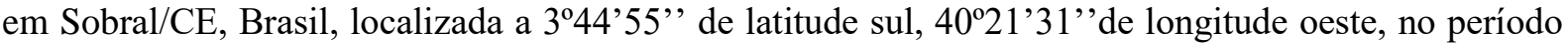
de 5 de fevereiro a 15 de maio de 2019, em uma área de $6,5 \times 6,0 \mathrm{~m}$. O plantio foi realizado manualmente, utilizando 12 mil sementes por hectare em sulcos com $5 \mathrm{~cm}$ de profundidade e espaçamento entre linhas de $70 \mathrm{~cm}$.

\section{Colheita e ensilagem das cultivares}

Para avaliação do efeito do estádio de maturação, as plantas foram cortadas e ensiladas nos estádios - E7 ou leitoso; E8 ou pastoso; E9 ou farináceo conforme descrito por Borém et al. (2014), assim como 
no estádio de grão duro (quando o grão estava passado da maturidade fisiológica) objetivando aumentar o número de amostras, ter maior variação nos dados para desenvolvimento de modelos com maior faixa de abrangência, aumentando sua robustez. As amostras foram ensiladas com cinco repetições para cada cultivar, totalizando 40 minis silos.

Tabela 1. Dias após a colheita dos sorgos BRS 658 e BRS Ponta Negra com épocas de corte definidas pelos estádios de maturação dos grãos (leitoso, pastoso, farináceo e duro)

\begin{tabular}{lcc}
\hline \multirow{2}{*}{ Estádios de maturação } & \multicolumn{2}{c}{ Colheita, dias após o plantio } \\
\cline { 2 - 3 } & BRS 658 & BRS Ponta Negra \\
\hline $1^{\circ}$ & 64 & 78 \\
$2^{\circ}$ & 70 & 86 \\
$3^{\circ}$ & 78 & 92 \\
$4^{\circ}$ & 84 & 99 \\
\hline
\end{tabular}

O corte das plantas foi realizado manualmente a uma altura de $20 \mathrm{~cm}$ do solo. Após o corte, o material foi processado em picadeira estacionária em partículas entre 2 e $3 \mathrm{~cm}$. A ensilagem foi realizada da planta inteira, em minis silos de PVC, com tampa tipo Bunsen adaptadas para permitir o escape dos gases oriundos da fermentação, com volume aproximado $\left(3,927 \mathrm{dm}^{3}\right)$ em densidade de compactação média de $500 \mathrm{~kg} / \mathrm{m}^{3}$. Em cada minis silo foi colocado $1,963 \mathrm{~kg}$ da massa picada.

A base dos minis silos continha $200 \mathrm{~g}$ de areia para deposição dos efluentes, a qual foi separada por telas para impedir contato direto com a massa ensilada. A compactação foi realizada com êmbolo de madeira. Os minis silos foram abertos três meses após da ensilagem e as análises foram realizadas no Laboratório de Nutrição Animal (LANA), da Embrapa Caprinos e Ovinos, em Sobral - CE.

\section{Análises laboratoriais}

Imediatamente após abertura dos minis silos, a massa ensilada foi homogeneizada, retirando-se aproximadamente $500 \mathrm{~g}$ de amostra para as análises laboratoriais. $\mathrm{O} \mathrm{pH}$ foi determinado em outra alíquota de amostra, conforme (Silva \& Queiroz, 2002). As amostras foram secas em estufa a $55^{\circ} \mathrm{C}$ e moídas em moinho tipo Willey a $1 \mathrm{~mm}$ (Silva \& Queiroz, 2002). Nas amostras foram determinados os teores de matéria seca (MS) (AOAC, 2005) e fibra em detergente neutro (FDN) (Senger et al., 2008). O teor de nitrogênio total (N) foi determinado em sistema de combustão (AOAC, 2005), utilizando um analisador de N LECO ${ }^{\circledR}$ CN628 (Leco Corp. St. Joseph, MI, EUA). As digestibilidades da matéria seca e da matéria orgânica foram determinadas por meio de ensaios de digestibilidade in vitro utilizando incubadora automática tipo MA443 (MA443, Marconi Equipamentos para Laboratórios Ltda., Piracicaba, SP, Brasil), conforme princípios da técnica de Tilley \& Terry (1963), com segunda etapa em solução de FDN utilizando a técnica adaptada por Senger et al. (2008).

\section{Coleta dos espectros}

A coleta dos espectros foi feita em instrumento NIR FOSS ${ }^{\odot} 5000$ (Foss NIR Systems Inc., Silver Spring, MD, USA) que possui intervalo espectral na faixa de 1100 a $2500 \mathrm{~nm}$ e resolução de $2 \mathrm{~nm}$. As amostras, antes de terem seus espectros coletados foram alocadas em estufa a $55^{\circ} \mathrm{C}$ por três horas, para padronizar o teor de umidade (Lyons \& Stuth, 1992).

\section{Análises quimiométricas}

Após a coleta dos espectros das amostras foi aplicada a técnica de Correção Multiplicativa de Sinal (MSC) (Chen et al., 2012) para correção de espalhamento, típico de reflectância de amostras sólidas.

A Análise de Componentes Principais (PCA), foi utilizada para a análise exploratória das amostras, a fim de avaliar a formação de agrupamentos (Lyra et al., 2010) tanto em relação ao cultivar de silagens de sorgo (BRS 658 e BRS Ponta Negra), quanto para o estádio de maturidade dos grãos no momento da ensilagem.

Em seguida, foi utilizada a ferramenta de classificação Modelagem Independente por Analogia de Classe (SIMCA) para identificar similaridade entre os espectros NIR das silagens de sorgo e dos estádios de maturidade. Essa técnica tem como base o cálculo da distância de cada amostra ao centro do modelo com o banco de dados para o qual se avalia a similaridade, a um nível de significância de 5\% (Balabin et al., 2010). 


\section{Análises estatísticas}

Para análise estatística descritiva utilizou-se o Software The Unscrambler versão 10.2 (Camo Inc, AS, Norway). Os dados de composição bromatológica entre cultivares e estádios, foram comparados por meio de análise de variância (teste F) e teste de comparação de médias. As médias foram comparadas pelo teste de Tukey $(\mathrm{P}<0,05)$, utilizando procedimento MIXED com medidas repetidas no tempo em esquema fatorial 2 × 4 (duas cultivares versus quatro estádios de maturação) com 5 repetições. Como ferramenta de auxílio às análises estatísticas, utilizou-se o programa computacional $\mathrm{SAS}^{\circledR}{ }^{\circledR} \mathrm{SAS}^{\circledR}$ Institute, versão 9.0).

\section{Resultados e discussão}

Valores médios de pH, MS, FDN, PB, DIVMS e DIVMO das silagens de sorgo de diferentes cultivares, em diferentes estádios de maturação dos grãos

Para valores de $\mathrm{pH}$, não houve efeito $(\mathrm{P}>0.05)$ dos estádios de maturação dos grãos dentro do cultivar BRS 658. Já para cultivar BRS Ponta Negra observou-se que o $\mathrm{pH}$ foi menor $(\mathrm{P}<0,05)$ para $\mathrm{o}$ estádio leitoso, quando comparada com os demais estádios. Houve diferença $(\mathrm{P}<0,05)$ também entre as duas cultivares, quando comparadas no estádio leitoso, sendo que o $\mathrm{pH}$ da cultivar 658 foi maior que o do BRS Ponta Negra. Apesar das diferenças observadas, os valores de pH estão dentro da faixa considerada ideal (3,6 a 4,2) para promover uma eficiente conservação da massa ensilada (McDonald, 1981).

Verificou-se interação $(\mathrm{P}<0,05)$ entre as cultivares e os estádios de maturação para os teores de matéria seca (Tabela 2), observando-se maior teor no estádio de maturação dos grãos duro e menor teor para os grãos leitoso, sendo que o pastoso foi diferente apenas do estádio leitoso e semelhante ao farináceo e duro. O leitoso também não apresentou diferença $(\mathrm{P}>0,05)$ em relação ao farináceo. Os teores de MS também apresentaram diferença significativa entre as cultivares, com maior valor observado para BRS 658 (32,5\%) e menor valor no BRS Ponta Negra (20,4\%). Os baixos teores de MS verificados no presente trabalho no BRS Ponta Negra, possivelmente estão relacionados ao fato do cultivar possuir um "stay green" maior em relação ao BRS 658, o material amadurece, mas permanece verde, com maior teor de umidade (Subudhi et al., 2000).

Tabela 2. Valores médios de pH, matéria seca (MS) e fibra em detergente neutro (FDN) das silagens de sorgo BRS 658 e BRS Ponta Negra com épocas de corte definidas pelos estádios de maturação dos grãos (leitoso, pastoso, farináceo e duro).

\begin{tabular}{|c|c|c|c|c|c|}
\hline \multirow{3}{*}{ Cultivar } & \multicolumn{4}{|c|}{ Estádios dos grãos } & \multirow{3}{*}{ Média } \\
\hline & Leitoso & Pastoso & Farináceo & Duro & \\
\hline & \multicolumn{4}{|c|}{$\mathrm{pH}$} & \\
\hline BRS 658 & $3,68 \mathrm{Aa}$ & $3,72 \mathrm{Aa}$ & $3,65 \mathrm{Aa}$ & $3,76 \mathrm{Aa}$ & $3,70 \mathrm{~A}$ \\
\hline BRS PN & $3,49 \mathrm{Bb}$ & $3,65 \mathrm{Aa}$ & 3,71Aa & $3,66 \mathrm{Aa}$ & $3,63 \mathrm{~A}$ \\
\hline \multirow[t]{2}{*}{ Média } & 3,59 & 3,69 & 3,68 & 3,71 & \\
\hline & \multicolumn{4}{|c|}{ MS\% } & Média \\
\hline BRS 658 & 27,45 & 33,15 & 31,68 & 37,73 & $32,50 \mathrm{~A}$ \\
\hline BRS PN & 18,81 & 20,79 & 20,81 & 21,24 & $20,41 \mathrm{~B}$ \\
\hline \multirow[t]{2}{*}{ Média } & $23,13 \mathrm{c}$ & $26,97 \mathrm{ab}$ & $26,25 b c$ & $29,49 \mathrm{a}$ & \\
\hline & \multicolumn{4}{|c|}{ FDN\% } & Média \\
\hline BRS 658 & 62,76 & 57,17 & 59,12 & 63,26 & $60,58 \mathrm{~B}$ \\
\hline BRS PN & 65,46 & 64,56 & 65,15 & 65,30 & $65,12 \mathrm{~A}$ \\
\hline Média & 64,11 & 60,87 & 62,14 & 64,28 & \\
\hline
\end{tabular}

pH - Potencial hidrogeniônico; MS - Matéria seca; FDN - Fibra insolúvel em detergente neutro. Médias seguidas por letras maiúsculas distintas na coluna diferem $(\mathrm{P}<0,05)$ entre si pelo teste de Tukey. Médias seguidas por letras minúsculas diferentes na linha diferem $(\mathrm{P}<0,05)$ entre si pelo teste de Tukey.

Os teores de FDN das silagens diferiram $(\mathrm{P}<0,05)$ entre as cultivares (Tabela 2), sendo verificado teor mais elevado para cultivar BRS Ponta Negra $(65,1 \%)$, fator que pode estar relacionado ao fato do cultivar possuir maior proporção de colmo em relação a massa total. Santos et al. (2013) em estudo de caracterização agronômica de cultivares de sorgo, relatou relação panícula, colmo e folhas de 15,7\%, $71,9 \%, 12,4 \%$, respectivamente, para a cultivar BRS Ponta Negra. Contudo, os teores observados situam-se dentro da faixa de 39,2 a 71,9\%, citada por White et al. (1988), para silagem de cultivares de sorgo. Conforme verificado, os parâmetros avaliados indicam que, independentemente da cultivar ou do estádio de maturação, as silagens apresentavam boa qualidade. 
Tabela 3. Estatística descritiva dos parâmetros de proteína bruta (PB), digestibilidade in vitro da matéria seca (DIVMS) e digestibilidade in vitro da matéria orgânica (DIVMO) da silagem de sorgo

\begin{tabular}{lcccc}
\hline Parâmetro & $\mathrm{N}$ & Média $(\%)$ & Min/Máx (\%) & DP \\
\hline PB & 40 & 7,95 & $5,69-10,45$ & 1,15 \\
DIVMS & 40 & 59,78 & $43,94-71,38$ & 7,74 \\
DIVMO & 40 & 60,33 & $43,87-71,64$ & 8,04 \\
\hline
\end{tabular}

$\mathrm{N}$ (número de amostras). Min/Máx (média mínima e máxima). DP (desvio padrão).

A composição bromatológica dos alimentos varia em função das características do próprio alimento, tratamento e processamento aos quais são submetidos. Quando observados os valores mínimos e máximos percebe-se uma grande variação entre esses valores. A maior amplitude nos valores dos parâmetros avaliados PB, DIVMS e DIVMO demostra que a estratégia utilizada para formar o banco de dados foi adequada por obter uma ampla variação, o que é desejado para obter modelos com maior abrangência, aumentando sua robustez e acurácia.

\section{Análise exploratória de amostras de silagem de sorgo e diferentes estádios de maturação dos grãos}

Como pode ser observado na figura 1A, houve um significativo espalhamento no perfil espectral, o que já era esperado para amostras sólidas, dado que, os espectros gerados podem ser afetados por diferenças na granulometria, umidade das amostras e dispersão da luz (Siesler et al., 2008). Para corrigir ou remover os efeitos causados nos espectros obtidos, foi empregado o pré-tratamento com MSC, cujo resultado pode ser observado na figura $1 \mathrm{~B}$.
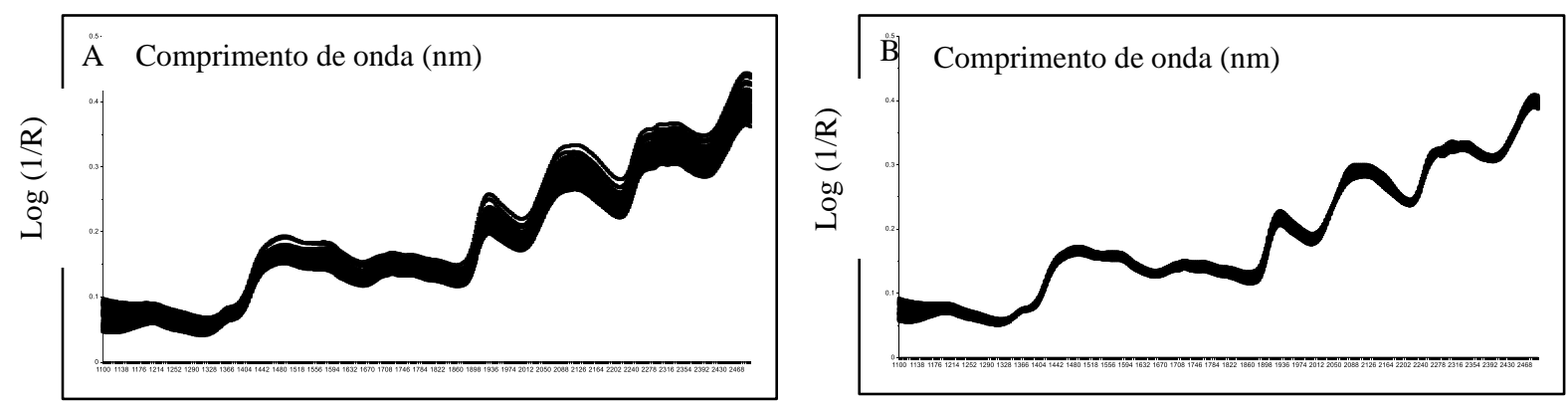

Figura 1. Espectros de 40 amostras de silagens de sorgo BRS 658 e BRS Ponta Negra, (A) Espectros brutos e (B) espectros utilizando o tratamento com MSC.

Observa-se que após o tratamento com MSC, houve uma redução na dispersão, o que traz ganhos na identificação da semelhança nos sinais avaliados, nas amostras de silagens de sorgo BRS 658 e BRS Ponta Negra. Segundo Sabin et al. (2004) o pré-tratamento com MSC melhora a linearidade do conjunto espectral, reduzindo as diferenças e destacando áreas que são responsáveis pelas diferenças entre as amostras.

Para avaliar a similaridade das amostras de silagem de sorgo BRS 658 e BRS Ponta Negra foi realizado uma análise de classificação SIMCA (Tabela 4).

Tabela 4. Classificação de amostras da silagem de sorgo BRS 658 e BRS Ponta Negra utilizando a análise de classificação SIMCA

\begin{tabular}{lcc|cc}
\hline \multirow{2}{*}{ Modelo } & \multicolumn{2}{c|}{ BRS 658 } & \multicolumn{2}{c}{ BRS Ponta Negra } \\
\cline { 2 - 5 } & Similar/Total & Grau de similaridade, $\%$ & Similar/Total & Grau de similaridade, \% \\
\hline BRS 658 & $20 / 20$ & 100 & $1 / 20$ & 5 \\
BRS Ponta Negra & $13 / 20$ & 65 & $20 / 20$ & 100 \\
\hline
\end{tabular}

Quando comparadas entre si, as amostras de silagem do mesmo cultivar de sorgo apresentaram grau de similaridade de $100 \%$, como era esperado (Tabela 4). No entanto, quando se avaliou a similaridade de amostras da silagem de sorgo BRS 658 com o banco de dados do sorgo BRS Ponta negra, a similaridade foi de apenas $5 \%$. Por outro lado, quando se avaliou a similaridade de cada amostra de BRS Ponta Negra em relação ao modelo do banco de dados do BRS 658 a similaridade foi de $65 \%$.

Observa-se que os bancos de dados de silagem do BRS Ponta Negra reconhecem com maior magnitude, como similares, as amostras do BRS 658, mas o modelo do sorgo BRS 658 considera similar somente uma pequena parte das amostras do BRS Ponta Negra. Esse resultado parece estar relacionado ao fenótipo dos cultivares e seu impacto no perfil químico dos dois materiais. A composição química das plantas no presente estudo mostrou diferença entre as cultivares no teor de FDN como observado na 
(Tabela 2) maior teor verificado para BRS Ponta Negra, o que implica em mudanças na química da planta, que por sua vez altera o perfil do espectro NIR, condizendo com o resultado observado na análise de semelhança SIMCA.

As plantas de sorgo que demostram elevada quantidade de colmos na massa de forragem são mais fibrosas, uma característica do cultivar BRS Ponta Negra. Oliveira et al. (2010) verificaram que as forragens que apresentaram maior porcentagem de colmos também apresentaram maiores teores dos componentes associados à parede celular vegetal.

A variabilidade do banco amostral, é uma característica importante para o desenvolvimento de calibrações robustas, que permitam uma maior amplitude de análise. Assim, a dissimilaridade observada entre as cultivares sugere que a utilização de informações de ambas enriquece o banco de dados e a qualidade do modelo. No entanto, é importante avaliar se as dissimilaridades não são tão significativas, a ponto de exigirem desenvolvimento de modelos independentes.

Para isso é importante avaliar a distribuição das amostras e a formação de padrões por métodos não supervisionados como a análise de componentes principais (PCA) para observar a distribuição das amostras que podem orientar a construção dos bancos de dados para desenvolvimento de modelos NIR (Fu \& Ying, 2016; Johnson et al., 2017). Para Muñiz et al. (2012), a técnica PCA reduz a dimensionalidade dos dados pelo ajuste linear dos dados originais (espectros) com a finalidade de reunir a maior variabilidade dos dados sem perda considerável da informação química. Pode-se observar na figura 2, que a distribuição das amostras das cultivares de sorgo confirmam os achados da análise SIMCA de que há regiões de conexão entre os dois bancos de dados, mas, ao mesmo tempo, amostras com destacada dissimilaridade. Também, maior variação (dispersão) observada para o banco de dados do BRS Ponta Negra, faz com que os limites de reconhecimento das amostras do BRS 658 sejam maiores e, portanto, maior possibilidade de serem consideradas similares, como demonstrado na avaliação SIMCA.

O estudo dos limites da elipse de Hotelling (estatística $\mathrm{T}^{2}$ de Hotelling) (Figura 2) permite avaliar a coerência de se considerar as duas cultivares como pertencentes a um mesmo banco de dados espectral, gerando uma informação adicional sobre a possibilidade de desenvolver modelos NIR combinando os dois materiais. Os limites observados na elipse da figura 2, demonstra que, com exceção de uma amostra pertencente ao cultivar BRS Ponta Negra, todas as outras amostras situam-se dentro dos limites da estatística $\mathrm{T}^{2}$, indicando que as dissimilaridades observadas agregam variação importante ao modelo, mas não parecem tão críticas, a ponto de sugerirem que o desenvolvimento de modelos NIR devam considerar as cultivares de forma individual.

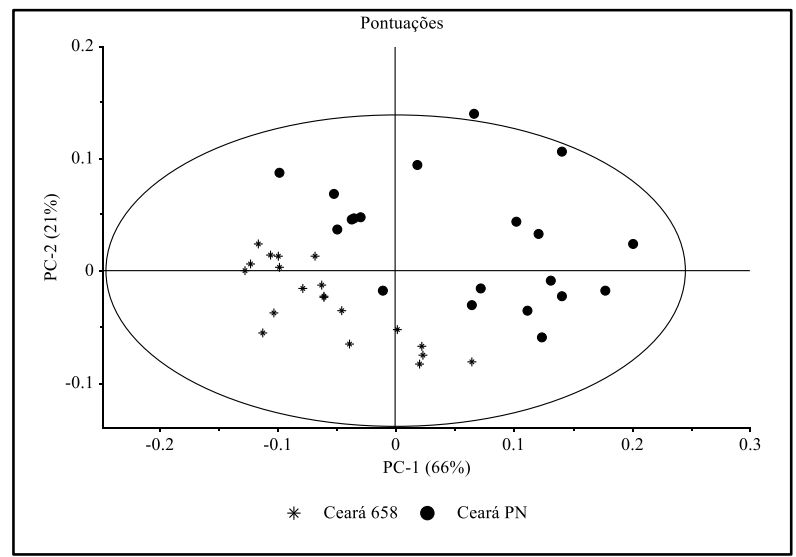

Figura 2. Análise exploratória (PCA) de amostras de silagens de sorgo BRS 658 e BRS Ponta Negra cultivadas no município de Sobral/CE. PC1 (66\%) versus PC2 (21\%) e Limites estabelecidos por Hotelling (elipse).

Para testar o grau de similaridade ou diferenças entre as amostras de silagem de sorgo BRS 658 e BRS Ponta Negra nos estádios dos grãos, leitoso, pastoso, farináceo e duro, foi realizada uma análise de classificação de SIMCA das amostras, considerando essas variáveis (Tabela 5). Baseado nesta classificação, as amostras da silagem de sorgo dentro da mesma cultivar obtiveram $100 \%$ de similaridade quando classificadas pelo estádio de maturação, como esperado (Tabela 5). 
A análise demonstrou também alta similaridade no BRS 658 entre os estádios grão duro e farináceo (80\%). Houve também baixa similaridade nos estádios leitoso e pastoso, demonstrando que ambos agregam variação ao modelo. Esses resultados demonstraram que a classificação SIMCA pode ser uma importante ferramenta para o planejamento no desenvolvimento de modelos NIR, pois essas diferenças relacionadas a mudanças químicas que ocorrem ao longo do processo de maturação, podem ser estimadas pela composição bromatológica da planta com implicação nos resultados do NIR.

Do estádio leitoso para pastoso há maior similaridade, provavelmente devido às fases iniciais de enchimento dos grãos, que à medida que avança no estádio, diminui a similaridade. Esse fato está relacionado às mudanças na fisiologia da planta com impacto na química, onde as plantas ao ficarem mais maduras, aumentam o teor de MS, principalmente devido ao aumento da fração fibrosa.

Os dados demonstram ainda grande similaridade do BRS Ponta Negra entre os estádios dos grãos leitoso e pastoso (80\% similaridade), evidenciando que o estádio leitoso apresenta informações similares ao pastoso. Estes resultados revelam também que a ferramenta de classificação utilizando a análise SIMCA, apresenta alta sensibilidade, classificando as amostras dentro da sua respectiva classe, e mostrou a sua especificidade, diferenciando aquelas amostras não pertencentes àquela classe.

As amostras da silagem de sorgo BRS 658 e BRS Ponta Negra obtiveram 100\% de similaridade quando classificadas no estádio leitoso e pastoso. De maneira geral híbridos tem uma formação de folhas e sistema radicular mais acelerado do que as linhagens ou variedades (Magalhaes et al., 2003). Isto pode ter ocasionado a maior similaridade verificada nos estádios de maturação dos grãos leitoso e pastoso de ambas as cultivares, fazendo com que, mesmo que a variedade BRS Ponta Negra avance na maturidade no estádio pastoso ainda tenha similaridade com leitoso do híbrido BRS 658. Associado a isto, outros fatores fisiológicos de cada cultivar podem estar envolvidos, como a característica de "stay green" da variedade BRS Ponta Negra ser mais pronunciada e mesmo que avance na maturidade no estádio pastoso ainda tenha similaridade com leitoso do híbrido BRS 658. Pescumo \& Igarasi (2013) descrevem que a característica de "stay green" conserva a planta verde por mais tempo durante a maturação dos grãos, por diminuir o teor de matéria seca da porção verde, visto que, quando os grãos estão no momento ótimo de colheita, a planta estará ainda com o caule verde e com muita umidade.

Conforme verificado, o modelo BRS 658 no estádio leitoso e pastoso tem alta similaridade com o estádio leitoso e pastoso do BRS Ponta Negra (100\%), isto é, o BRS 658 apresenta uma variação similar às amostras de BRS Ponta Negra nos estádios leitoso e pastoso, já o modelo BRS Ponta Negra apresentou menor similaridade em relação ao BRS 658 nos estádios leitoso e pastoso (40\% e 20\%) respectivamente.

A análise da PCA, considerando os estágios de maturação demonstrou uma semelhança entre as amostras nos estádios leitosos das duas cultivares, no estádio leitoso com pastoso, farináceo e duro (Figura 3).

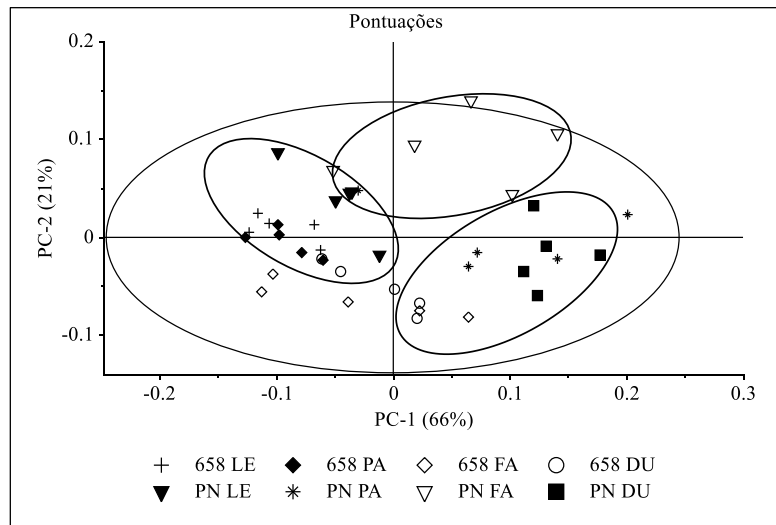

Figura 3. Análise exploratória de amostras de silagens de sorgo BRS 658 e BRS Ponta Negra, com épocas de corte definidas pelos estádios de maturação dos grãos (leitoso, pastoso, farináceo e duro). E Limites estabelecidos por Hotelling (elipse). 

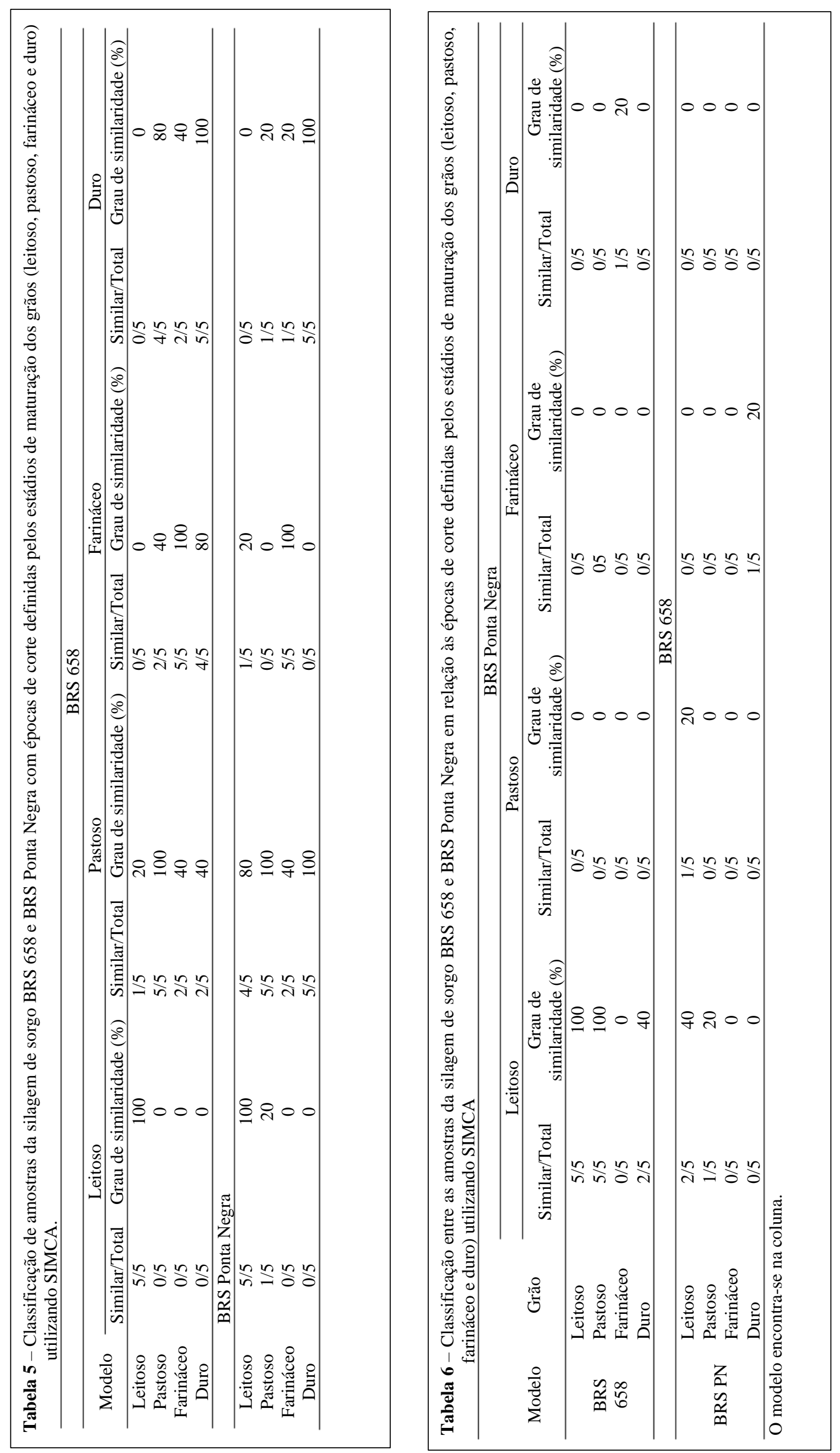
Verificou-se ainda, similaridade entre os estádios leitoso, pastoso, farináceo e duro de cada cultivar, assim como observado na (Tabela 5) que demonstrou similaridade de $100 \%$ quando classificadas dentro da sua própria cultivar. Não foi observado agrupamento relacionados aos estádios de maturação dos grãos das cultivares que ultrapassassem os limites de Hotelling, o que indica que, as diferenças observadas na análise SIMCA (Tabela 6) e na PCA (figura 3) agregam robustez ao modelo, mas ao mesmo tempo indicam que os estádios de maturidade podem compor um único banco de dados para o desenvolvimento de modelos NIR.

\section{Considerações finais}

A análise exploratória indica que é importante considerar a cultivar e os estádios de maturidade dos grãos para o desenvolvimento de modelos NIR de silagem de sorgo.

A análise dos espectros NIR das cultivares BRS 658 e BRS Ponta Negra, bem como dos estádios de maturidade no momento da ensilagem indicam que as dissimilaridades observadas agregam variabilidade ao modelo, mas que, ao mesmo tempo, não são tão significativas a ponto de sugerirem desenvolvimento de modelos separados, permitindo a fusão dos dados para desenvolvimento de um único modelo NIR.

\section{Referências bibliográficas}

AOAC. (2005). - Association Official Analytical Chemist. In Gaitherburg (Ed.), Official Methods of Analysis (Official M). AOAC.

Avelino, P. M., Neiva, J. N. M., Araujo, V. L., Alexandrino, E., Bomfim, M. A. D., \& Restle, J. (2011). Composição bromatológica de silagens de híbridos de sorgo cultivados em diferentes densidades de plantas. Revista Ciência Agronômica, 42(1), 208-215.

Balabin, R. M., Safieva, R. Z., \& Lomakina, E. I. (2010). Gasoline classification using near infrared (NIR) spectroscopy data: Comparison of multivariate techniques. Analytica Chimica Acta, 671(12), 27-35. https://doi.org/10.1016/j.aca.2010.05.013.

Borém, A., Pimentel, L., \& Parrella, R. (2014). Sorgo: do plantio a colheita. Universidade Federal de Viçosa.

Chen, Y., Xie, M., Zhang, H., Wang, Y., Nie, S., \& Li, C. (2012). Quantification of total polysaccharides and triterpenoids in Ganoderma lucidum and Ganoderma atrum by near infrared spectroscopy and chemometrics. Food Chemistry, 135(1), 268-275. https://doi.org/10.1016/j.foodchem.2012.04.089.

Faustino, T. F., Dias, N. C., Leite, R. F., Silva, F. F. G., Florentino, L. A., \& Rezende, A. V. (2018). Utilização da silagem de grão de sorgo reidratado na alimentação animal. Nucleus Animalium, 10(2), 47-60.

Fu, X., \& Ying, Y. (2016). Food safety evaluation based on near infrared spectroscopy and imaging: a review. Critical Reviews in Food Science and Nutrition, 56(11), 1913-1924. https://doi.org/10.1080/10408398.2013.807418.

Johnson, J. R., Carstens, G. E., Prince, S. D., Ominski, K. H., Wittenberg, K. M., Undi, M., Forbes, T. D. A., Hafla, A. N., Tolleson, D. R., \& Basarab, J. A. (2017). Application of fecal near-infrared reflectance spectroscopy profiling for the prediction of diet nutritional characteristics and voluntary intake in beef cattle. Journal of Animal Science, 95(1), 447-454. https://doi.org/10.2527/JAS.2016.0845.

Lyons, R. K., \& Stuth, J. W. (1992). Fecal NIRS equations for predicting diet quality of free-ranging cattle. Journal Range Manage, 45, 238-244. https://doi.org/10.2307/4002970.

Lyra, W. S., Silva, E. C. da, Araújo, M. C. U., Fragoso, W. D., \& Veras, G. (2010). Classificação periódica: um exemplo didático para ensinar análise de componentes principais. Química Nova, 33, 1594-1597. https://doi.org/10.1590/s0100-40422010000700030.

Magalhaes, P. C., Duraes, F. O. M., \& Rodrigues, J. A. S. (2003). Fisiologia da planta de sorgo. Embrapa Milho e Sorgo-Comunicado Técnico, 1-12.

McDonald, P. (1981). The biochemistry of silage. John Wiley \& Sons, Ltd.

Muñiz, G. I. B., Magalhães, W. L. E., Carneiro, M. E., \& Viana, L. C. (2012). Fundamentos e estado da arte da espectroscopia no infravermelho próximo no setor de base floresta. Ciência Florestal, 22, 865-875. https://doi.org/10.5902/198050987567.

Neumann, M., Mühlbach, P. R. F., Nörnberg, J. L., Ost, P. R., Restle, J., Sandini, I. E., \& Romano, M. A. (2007). Características da fermentação da silagem obtida em diferentes tipos de silos sob efeito 
do tamanho de partícula e da altura de colheita das plantas de milho. Ciência Rural, 37(3), 847-854. https://doi.org/10.1590/s0103-84782007000300038.

Oliveira, L. B., Pires, A. J. V., Viana, A. E. S., Matsumoto, S. N., Carvalho, G. G. P., \& Ribeiro, L. S. O. (2010). Produtividade, composição química e características agronômicas de diferentes forrageiras. Revista Brasileira de Zootecnia, 39(12), 2604-2610.

Penna, A., Borges, A. L., Gonçalves, L. C., Rodrigues, J. A., Gomes, S., Penna, C., Borges, I., Rodrigues, N. M., \& Silva, R. (2011). Valor nutritivo de seis híbridos de sorgo com capim-sudão avaliados em três cortes e em duas épocas de semeadura. Revista Brasileira de Milho e Sorgo, 9(2), 147-161.

Pescumo, D. P., \& Igarasi, M. S. (2013). Híbridos de milho e sorgo para silagem na alimentação de bovinos leiteiros. PUBVET, 7, 420-548. https://doi.org/10.22256/pubvet.v7n6.1513.

Prieto, N., Andrés, S., Giráldez, F. J., Mantecón, A. R., \& Lavín, P. (2006). Potential use of near infrared reflectance spectroscopy (NIRS) for the estimation of chemical composition of oxen meat samples. Meat Science, 74(3), 487-496. https://doi.org/http://dx.doi.org/10.1016/j.meatsci.2006.04.030

Restle, J., Pacheco, P. S., Alves Filho, D. C., Freitas, A. K., Neumann, M., Brondani, I. L., Pádua, J. T., \& Arboitte, M. Z. (2006). Silagem de diferentes híbridos de milho para produção de novilhos superjovens. Revista Brasileira de Zootecnia, 35(5), 2066-2076. https://doi.org/10.1590/S151635982006000700026

Ribeiro, C. G., Gonçalves, L. C., Rodrigues, J. A., Rodriguez, N. M., Borges, I., Borges, A. L. C., Saliba, E. O., Castro, G. H., \& Ribeiro Junior, G. O. (2007). Padrão de fermentação da silagem de cinco genótipos de sorgo. Arquivo Brasileiro de Medicina Veterinária e Zootecnia, 59(6), 1531-1537.

Ribeiro, V. L., Batista, Â., Carvalho, F. F. R., Silva, M. J. M. S., Mattos, C. W., \& Alves, K. S. (2009). Seletividade e composição da dieta ingerida por caprinos recebendo alimentação à vontade e restrita. Revista Brasileira de Ciências Agrárias, 4(1), 91-94.

Sabin, J. G., Ferrão, M. F., \& Furtado, J. C. (2004). Análise multivariada aplicada na identificação de fármacos antidepressivos. Parte II: Análise por componentes principais (PCA) e o método de classificação SIMCA. Revista Brasileira de Ciências Farmacêuticas, 40, 387-396. https://doi.org/10.1590/s1516-93322004000300015.

Santos, R. D., Pereira, L. G. R., Neves, A. L. A., Rodrigues, J. A. S., Costa, C. T. F., \& Oliveira, G. F. (2013). Agronomic characteristics of forage sorghum cultivars for silage production in the lower middle San Francisco Valley. Acta Scientiarum. Animal Sciences, 35, 13-19. https://doi.org/10.4025/actascianimsci.v35i1.13072.

Senger, C. C. D., Kozloski, G. V, Sanchez, L. M. B., Mesquita, F. R., Alves, T. P., \& Castagnino, D. S. (2008). Evaluation of autoclave procedures for fibre analysis in forage and concentrate feedstuffs. Animal Feed Science and Technology, 146(1-2), 169-174. https://doi.org/10.1016/j.anifeedsci.2007.12.008.

Siesler, H. W., Ozaki, Y., Kawata, S., \& Heise, H. M. (2008). Near-infrared spectroscopy: principles, instruments, applications. John Wiley \& Sons.

Silva, D. J., \& Queiroz, A. C. (2002). Análise de alimentos: métodos químicos e biológicos (3rd ed.). Universdiade Federal de Viçosa.

Silva, K. J., Menezes, C. B., Tardin, F. D., Emygidio, B. M., \& Souza, V. F. (2013). Seleção de híbridos de sorgo granífero cultivados no verão em três localidades. Revista Brasileira de Milho e Sorgo, 12(1), 44-53.

Subudhi, P. K., Rosenow, D. T., \& Nguyen, H. T. (2000). Quantitative trait loci for the stay green trait in sorghum (Sorghum bicolor L. Moench): consistency across genetic backgrounds and environments. Theoretical and Applied Genetics, 101(5), 733-741. https://doi.org/10.1007/s001220051538.

Tilley, J. M. A., \& Terry, R. A. (1963). A two-stage technique for the in vitro digestion of forage crops. Grass and Forage Science, 18(2), 104-111.

White, J., Bolsen, K., Kirch, B., \& Pfaff, L. (1988). Selecting forage sorghum cultivars for silage. Manhattan: Kansas Agricultural Experimental Station, 1-8.

Histórico do artigo:

Recebido: 1 de agosto de 2021

Aprovado: 3 de setembro de 2021

Disponível on-line: 27 denovembrode 2021

Licenciamento: Este artigo é publicado na modalidade Acesso Aberto sob a licença Creative Commons Atribuição 4.0 (CC-BY 4.0), a qual permite uso irrestrito, distribuição, reprodução em qualquer meio, desde que o autor e a fonte sejam devidamente creditados. 